\title{
"It never happened to me, so I don't know if there are procedures": identification and case management of torture survivors in the reception and public health system of Rome, Italy
}

\author{
Caterina Spissu, *, Gianfranco De Maio, *, Rafael Van den Bergh, *, Engy \\ Ali, ${ }^{2}$, Emilie Venables, ${ }^{* * *}$, Doris Burtscher, $* * *$, Aurelie Ponthieu, ${ }^{*}$, Mario \\ Ronchetti, ****, Narciso Mostarda, ****, Federica Zamatto*
}

\section{Key point of interest:}

- Staff who come into contact with refugees should be trained in how to sensitively identify torture survivors and to refer them to appropriate services for rehabilitation.

\section{Abstract \\ Background: Access and linkage to care for migrant torture survivors is contingent on their identification and appropriate referral. However, appropriate tools for identification of survivors are not readily available, and the (staff of) reception systems of host countries may not always be equipped for}

*) Médecins Sans Frontières - Operational Centre Brussels

$\star \star$ ) University of Cape Town, School of Public Health and Family Medicine, Division of Social and Behavioural Sciences, Cape Town, South Africa

$\star \star \star)$ Médecins Sans Frontières, Vienna Evaluation Unit, Vienna, Austria

$\star \star \star \star$ ) Azienda Sanitaria Locale Rome 6, Rome, Italy Correspondence to: caspissu@gmail.com this task. This study explores practices in the identification and case management of torture survivors in the reception structures and in the public health sector in Rome, Italy. Method: Data were analysed manually and codes and themes generated. Results: A non-homogeneous level of awareness and experience with torture survivors was observed, together with a general lack of knowledge on national and internal procedures for correct identification of torture survivors. Identification and case management of torture survivors was mainly carried out by non-trained staff. Participants expressed the need for training to gain experience in the identification and management of torture survivors' cases, as well support and increased resources at both the reception and public health system levels. Conclusions: The crucial process of identification and prise en charge of survivors of torture among migrant and refugee populations is relegated to nontrained and inexperienced professionals at different levels of the reception system and public health care sector, which may carry a risk of non-identification and 
possible harm to survivors. Additional resources and structured interventions are urgently needed, in the form of developing procedures, training, and adapted multidisciplinary services.

Keywords: Torture; asylum seeker; refugee; identification; case management

\section{Introduction}

Torture survivors constitute a sizeable proportion of mixed-migration flows (OHCHR, 2017), with an estimated 5 to $35 \%$ among refugee populations (Baker, 1992). In addition to the torture, persecution and abuse faced in their country of origin, refugees and migrants are exposed to violence and ill-treatment during the long and perilous journey to reach safety, and they also face a variety of post-migration difficulties (Carswell, Blackburn, \& Barker, 2011). This can constitute a challenge for countries faced with mixed flows, as detection and care for survivors of torture may be complex and can require a high level of specialisation (Wenzel, 2007). While State signatories of the United Nations Convention Against Torture (UNCAT) are obliged to offer rehabilitation services for survivors of torture, this is not systematically provided. Even in countries where rehabilitative services—such as medical and psychological care, along with legal and social support - are provided, access is challenging for survivors of torture in transit or in a post-migratory condition, due to cultural and language barriers, the sense of confusion and disorientation upon arrival in a new context (Kirmayer, Narasiah, Munoz, Rashid, Ryder, Guzder, et al., 2011), and the sense of isolation and distrust which is a common feature of individuals who

\section{Acronyms}

ASL: Azienda Sanitaria Locale [Local Health Authority]

CARA: Centri Accoglienza Richiedenti Asilo [Reception Centres for Asylum Seekers]

CAS: Centri Accoglienza Straordinaria [Emergency Reception Centres]

CDA: Centri di Accoglienza [Reception centres]

CIR: Consiglio Italiano Rifugiati [Italian Council for Refugees]

CPSA: Centri di Primo Soccorso e Assistenza [Centres for First Aid and Assistance]

CSM: Centro di Salute Mentale [Public Mental Health Department]

INMP: Istituto Nazionale per la promozione della salute delle popolazioni Migranti e per il contrasto delle malattie della Povertà [National Institute for Health, Migration and Poverty]

McT: Medici contro la Tortura [Doctors against torture]

MeDU: Medici per i Diritti Umani [Doctors for Human Rights]

MoH: Ministero della Salute [Ministry of Health]

MoI: Ministero dell'Interno [Ministry of the Interior]

MSF: Médecins Sans Frontières [Doctors without Borders]

NHS: National Health System SPRAR: Sistema di Protezione per Richiedenti Asilo e Rifugiati [Protection System for Asylum Seekers and Refugees] 
have experienced torture (Sousa, 2013). These challenges are compounded by a general lack of appropriate tools for the identification of torture survivors, and can prevent or delay identification and referral of torture survivors to specialised care. Identification and referral are essential to prevent physical and mental conditions from deteriorating and becoming chronic (OSCE, 2016), or from impacting the accuracy of the incident account (Yawar, 2004) to the determining/adjudicating authorities; in Italy the Territorial Commissions in first instance, and the Civil Courts in case of appeal (OSCE, 2016; Towers, Reventlow, de Rengervé, de Witte, 2016).

In recent years, Italy has experienced a fluctuating and growing influx of mixedmigration flows, mainly arriving through the Central Mediterranean Route (Frontex, 2017). In 2016, it became the first entry point in Europe for migrants and refugees, with 181,436 migrants disembarking in the country after being rescued at sea. According to official data, the main nationalities declared at arrival are Nigerian, Guinean, and Ivorian (UNHCR, 2017). Prior to arrival in Italy, many transited for weeks or months in Libya, where they were confronted with violence, torture, arbitrary detention, ill-treatment and forced labour (UNSMIL, 2016). The reception system in Italy is overstretched in its attempts to respond to the needs of the migrant population hosted in both ordinary and emergency reception facilities across the country. With regards to the obligation to provide access to redress-including rehabilitation - to survivors of torture, Italy has been a signatory to the UNCAT from 1989 but has only recently introduced a bill criminalising torture. This bill does not, however, contain provisions for the redress and the overall rehabilitation of survivors of torture. Italy is one of the few European states which does not legislatively foresee an identification procedure of torture survivors during the asylum interview process (Towers, Reventlow, de Rengervé, de Witte, 2016). Nevertheless, the Italian Ministry of Health $(\mathrm{MoH})$ has newly issued guidelines on the psychological treatment of refugees who have faced torture or other forms of violence (Ministry of Health, 2017), though it is unclear whether any form of training or sensitisation on their use will be provided. Refugees who are survivors of torture are also included among the vulnerable categories listed by the Law Decree $142 / 2015$, which recognises their specific reception needs in compliance with the European Reception Directives (European Union, 2013).

Such developments in legislation seem to collide with the reality of the response that survivors of torture receive in the country. A number of specialised services for survivors of torture exist in Italy, including a Médecins Sans Frontières (MSF) clinic opened in Rome in 2015. In this clinic, most cases come from reception structures in the Rome province. However, anecdotal figures show that many referred individuals are not survivors of torture, with approximately $33.5 \%$ being considered out of scope following in-depth assessment at the MSF clinic which took place during the period October 2015-December 2017. Additionally, numbers of self-referred cases are increasing (from $4,3 \%$ in 2015 to $37 \%$ at the end of 2017), suggesting that there is a gap in the identification and referral processes.

Understanding the challenges in identification and referral is essential for 
improving referrals and for enhancing the possibility of survivors of torture accessing rehabilitation services. However, there is limited published evidence on this topic. While a 2016 review assessed the challenges of identifying victims of torture in various national asylum systems in Europe, North America and the Pacific, it focused mainly on organisational and procedural issues, and did not fully address the challenges and needs at the level of the frontline workers in the reception systems (Towers, Reventlow, de Rengervé, de Witte, 2016). We therefore conducted a qualitative study investigating practices in the identification and management of torture survivors' cases in the Italian reception and health contexts, and specifically in the reception centres and $\mathrm{MoH}$ sub-districts in the metropolitan area of Rome.

\section{Method'}

\section{Study design}

This is a qualitative study, based on indepth interviews with care providers at reception centres, general practitioners, and the syndromic teams (tasked with disease

1 This research was conducted through the Structured Operational Research and Training Initiative (SORT IT), a global partnership led by the Special Programme for Research and Training in Tropical Diseases at the World Health Organization (WHO/TDR). The model is based on a course developed jointly by the International Union Against Tuberculosis and Lung Disease (The Union) and Medécins Sans Frontières (MSF/Doctors Without Borders). The specific SORT IT programme which resulted in this publication was jointly developed and implemented by the Centre for Operational Research, The Union, Paris, France and the Operational Research Unit (LuxOR), MSF Brussels Operational Centre, Luxembourg. control) at the sub-district levels of the (Azienda Sanitaria Locale)-District 6 (ASL) in Rome, covering the southern metropolitan territory. Practitioners from the MSF rehabilitation of victims of torture clinic in Rome were involved in the study design, and facilitated its implementation. As the research did not directly involve survivors of torture, they were not involved in the design or implementation of the study.

Study setting - the reception system in Italy Migrants and refugees making their way to Italy typically arrive by sea in the southern regions of the country (UNHCR, 2017; Ministry of the Interior, 2017. Cruscotto Statistico), most commonly after being rescued at sea. Once registration and finger-printing procedures are finalised, migrants and refugees are transferred to the reception structures throughout the country. In Italy, the reception of those seeking protection is managed by the Ministry of the Interior (MoI) through the Department of Civil Liberties and Immigration. The reception system consists of different types of reception facilities for the lodging of international protection seekers across all regions in Italy (Decree Law, no. 142, 2015):

- first aid and assistance structures (CPSA), mainly located at disembarkation points (first phase).

- collective/governmental centres (CDA and CARA (second phase).

- reception by the SPRAR (Protection System for Asylum Seekers and Refugees) (third phase).

- reception in extraordinary/temporary structures (CAS) is foreseen where there is no space in the governmental centres or in SPRAR. In fact, the majority of 
protection seekers are hosted in CAS

$(78 \%)$ and in governmental centres

(8.5\%) (Ministry of the Interior, 2017.

Cruscotto Statistico).

In governmental and CAS centres, a number of services such as provision of food and non-food items, health care assistance, legal information, administrative assistance, and social and psychological support should be ensured (Ministry of the Interior, 2017. Schema di Capitolato). In SPRAR, in addition to the services provided in governmental centres and CAS, services aiming at promoting socio-economic inclusion (SPRAR, 2017) are provided: these include orientation to employment and enrolment in training courses. The composition of reception centre staff includes both general workers and specialised staff such as social and legal workers, cultural mediators, psychologists and in some cases nurses and/or doctors. Although the SPRAR system is dedicated to the reception and integration of protection seekers and refugees, its capacity is limited and it currently hosts only $13.5 \%$ of those applying for international protection.

In 2015, syndromic teams were created at a sub-district level within Rome ASL-6: the task of these teams is the prevention of outbreaks such as tuberculosis and scabies among the migrant population. Each subdistrict team consists of one medical doctor, one nurse and one social worker. Sociomedical activities include the provision of medical services to migrants/refugees, physical and psycho-social support for conditions related to torture and ill-treatment, and the monitoring of health conditions in the reception structures. All sub-district teams work under the coordination of the ASL-6 district team consisting of a psychologist, a social worker, a medical doctor and a number of technical referents.

According to the administrative status of the migrant/refugee hosted in the reception centre a general practitioner should be assigned. However, due to administrative delays or obstacles in the registration, often entitled migrants/refugees do not have a general practitioner assigned.

Workers in the SPRAR and CAS are assisted by cultural mediators, a cadre of workers whose responsibilities and tasks are aimed at improving mutual understanding, and facilitating access to public services and the process of integration for immigrants (Ministry of Interior, 2009).

Guidelines on the identification and referral of possible cases of torture or ill-treatment were issued in 2017 by the Ministry of Health, to health staff and reception staff alike. The guidelines stipulate a short training for reception centre staff on the issue of identification of cases of torture, as also specified in Decree 142, art. 17 , clause 8 . The implementation of these guidelines is however a regional responsibility, and is therefore highly dependent on the regional resources and the presence of actors at local/regional/ national level. In Rome province, there are seven service providers to which cases of torture and ill-treatment can be refferred: the Istituto Nazionale per la promozione della salute delle popolazioni Migranti e per il contrasto delle malattie della Povertà (INMP), the SaMiFo clinic, a joint public and private initiative (ASL 1 and Centro Astalli), the Consiglio Italiano per Rifugiati (CIR), Medici contro la Tortura (McT), CARITAS, MSF and Medici per i Diritti Umani (MeDU) (De Maio, Pettinicchio, 2018). The range of services provided differs from one service 
provider to another, however, it might include medical care, psychological and psychiatric support, physiotherapy, legal and social services, and provision of medical, legal and psychological certification.

\section{Study population}

Professionals were purposively selected in order to gain a range of the different professions for the interviews. A total of 28 in-depth interviews were conducted with the following categories of professionals:

- Reception officers in six reception centres: 15 interviews were conducted with nurses, psychologists, social and legal workers and cultural mediators.

- Syndromic teams in charge of reception centres in three sub-districts of ASL-6: 11 in-depth interviews were conducted with medical doctors, nurses, and social workers.

- General practitioners assigned by the local health system: two in-depth interviews were conducted with medical doctors.

All participants were frontline workers interacting at reception and health system level with the migrant/refugee population. Only one person refused to participate when asked.

\section{Exclusion criteria: Reception officers in} reception centres and health practitioners in the ASL- 6 district who had received training sessions by MSF on the identification and management of survivors of torture were excluded from the study before the initiation of the interviews.

Selection and recruitment of study population: Reception centres and sub-district teams in the ASL-6 district were purposively selected based on discussions with the social worker of the district team of ASL- 6 and the project coordinator of the MSF rehabilitation clinic. The selection of reception structures was based on the location of the reception centres, the characteristics of the hosted migrant and refugee population (mixed gender and age, adult males, families, women and accompanied minors), and the capacity and status of centres (SPRAR and CAS structures). To ensure that a variety of reception centres were considered in the study, we included two centres designated for adult males, one centre for women, accompanied minors and families, one centre for women and accompanied minors, and one centre for men and families.

Governmental centres such as CARA were excluded, as these structures have a larger capacity and are usually intended to host the migrant and refugee population for short periods of time. Likewise, structures dedicated to unaccompanied minors were disregarded, as the MSF clinic for rehabilitation of survivors of torture mainly sees adult survivors. Subdistrict teams with an incomplete working team were also excluded.

General practitioners were selected through the reception structures: over the course of the interviews with the reception centre staff, contact information of general practitioners assigned by the National Health System was obtained.

Once the selection was completed, the ASL-6 district sent an informative note to centres and sub-district teams to introduce the study and its content, and facilitated contact between the principal investigator (first author) and the staff of the reception centres and sub-district teams. The 
first author then contacted and visited the staff of the sub-district teams, the selected reception centres and the general practitioners to present the study and request their participation. The interviews were conducted in the ASL-District of Rome by the first author.

\section{Data collection}

The study took place between July and September 2017. Data was collected by the first author, who is a member of the MSF coordination team in Italy, working in the advocacy department. Interview questions were initially elaborated by the first author and validated by two experienced coauthors; questions were also shared and discussed with some of the MSF clinic staff. Interviews were audio-recorded upon agreement of participants and in-depth interview guides with open-ended questions were used. On a few occasions, manual notes were also taken during the interview. The length of the interviews varied from 40 minutes to approximately two hours. The language used in the interview was Italian, which is the native language of the first author and most of the participants. One interview was conducted in both Italian and English, as the interviewee whose native language was English found it easier to use the native language.

\section{Data analysis}

An external transcriber-translator was hired for the translation and transcription of the audio files, which were transcribed and translated verbatim from Italian to English. The first author verified the accuracy of both the translation to English and its transcription by listening to the audio-recordings and reading the transcripts. The transcripts were then re-read several times by the first author and one of the co-investigators, and were subsequently manually coded and analysed line by line. No data analysis software was used during the analysis process. A thematic content analysis was used, following an approach in which the researcher becomes familiar with the data, generates codes, searches for and names themes, whilst continuously reviewing and refining the themes that arise (Creswell, 2007; Braun, Clarke, 2006.). The coding framework was developed based on pre-identified themes as well as themes that emerged during data collection and discussions with the study team who were familiar with the data and the context. Neutrality was ensured by having the second investigator, who was not present during the interviews, review and code the transcripts in parallel. Differences in interpretation were resolved through discussion between the investigators.

\section{Informed consent and confidentiality}

Written informed consent was obtained from all interviewees before starting the interviews. All participants read and understood the informed consent in Italian, and translation was thus not necessary. A non-disclosure agreement was signed by the translatortranscriber to ensure that confidentiality of data would be maintained. All identifying information, including names of participants, reception centres, indication of sub-districts, and references to names or locations, was removed from transcripts before analysis.

\section{Ethical approval}

The study was approved by the Ethics Review Board of MSF (Geneva, 
Switzerland) and by the Lazio 2 Ethics Committee (Rome, Italy).

\section{Results}

The main themes identified in this study included participants' knowledge of the definition of torture and (identification) procedures, practices and challenges in identification/detection, and case management.

\section{Identifying survivors of torture- practices and gaps}

When questioned on the process of identification, many professionals reported a lack of awareness or an absence of standardised procedures at national and internal levels to correctly identify torture survivors. They also expressed limited knowledge and doubts on the effectiveness of the guidelines recently issued by the Ministry of Health.

"I miraculously stumbled upon these guidelines on torture. That was recently!" Social worker - T1

"I have them [MoH guidelines] on my tablet. I read those and I read the Istanbul Protocol but I think that for a reception officer or an ASL professional they don't have much practical value in managing daily tasks and meeting guests, it is for a higher level. In any case the sub-district team in ASL does not have the skills for that. The information has no practical relevance for the ASL sub-district team or for a reception officer, so we rely on instinct and our own common sense." Social worker-T3

"There are guidelines to be followed. The latest is from May 2017, for political refugees, and it does mention torture victims, but I can't say exactly which law this is. They were issued by the Ministry (...) for Social Policies." Social worker-T10

"I must confirm there is no dedicated [internal] procedure. It would be beneficial, very beneficial...” Psychologist-T13

Participants showed different degrees of knowledge and understanding when asked to define torture and degrading treatment. A lack of prior experience with torture survivors was also observed. The type and level of violence reported by migrants in relation to their journey in Libya, as well as trafficking episodes, were often identified as torture.

'I can intuit something because I've heard someone talk, I've seen reports on TV. I've read books, articles... I've read magazines and so on. But first-hand experience, I've never had." Health practitioner-T16

"How would I define torture? An inhumane act." Legal advisor-T2

"Previously my idea of torture was, say, I am a military, an official in a dictatorship, I torture someone to get information, because there is political opposition. But here I discovered there is another kind of torture, which is gratuitous... with no real reasons." Health practitioner-T7

"[T]hen there is Libya. And here we can avert our gaze, because what is happening in Libya is unspeakable, whether you are there for one day, two days or six months. (...). The women who went through Libya and suffered rape, gang rape, imprisonment, what is that? (...) Well I don't think they are held by the military, or by officials, but that's still torture.” Psychologist-T5 
"We saw cases of traditional or ritual conditioning when they leave for Italy. To ensure they will compensate for this travel, which is paid by third parties, they undergo a sort of voodoo ritual which (...), keeps them in a condition of constant stress, ... if the person does not pay the debt, damage would be done through this ritual to this person or to their loved ones. This is a type of psychological torture (...) Almost everyone travelled through Libya, ..., some were openly sold in these sex houses, and they were tortured in sexual terms, because they were forced to agree to these actions, for various reasons, because they were imprisoned, threatened, or had to pay a ransom." Cultural mediator - 66

"Torture is a situation in which a person is nullified as an individual. Practices are put in place to collect information from the person tortured, who for this reason is subject to repeated mistreatment (...) The essential difference is maybe that in torture there is an objective to gather information, the others are conditions of general violence." Psychologist - T8

Overall, the identification of torture survivors can occur in all of the stages of the reception process by reception officers or health practitioners in the public health sector. It can happen during the preparation for a Commission hearing, when physical scars are noticed during a medical consultation, in counselling sessions, during the observation of the refugees and migrants by reception officers, or at any other point in the reception process. However, signs and symptoms were seen as arduous to "read" and often certain behavioural traits such as isolation and/or aggressive conduct were perceived as "difficult". The below quotations show the differing ways that professionals suspected or identified torture in the migrant and refugee populations they worked with.

"With a visit we can see if they have physical damage, so to speak. But we don't know if these are signs of torture. Psychologically you can look at them, observe them a moment (...) but I really don't know how to start." Health practitioner-T15

"If they stay all day in the room and don't eat, something isn't right. If he argues and discusses with everyone, that is another symptom. If when seeing a reception officer he starts asking a thousand things, there is a state of anxiety (...) For sure physically you can tell, you see wounds, scars. On the psychological level, it's harder. It depends on the reception officer's sensitivity to understand." Legal advisor -T2

"You can recognise victims of torture from how they are in the centre. It's not that you automatically recognise them but you notice who is doing worse than the others. They are isolated, may have aggressive reactions. Sleeping problems are very common, sleeping pattern changes, nightmares, recurring flashbacks. (...) It is evident, some cases are more evident, and some are more hidden." Psychologist-T8

Other obstacles in the identification of torture survivors indicated by the interviewees included language barriers and refusal to talk. Others mentioned survivors having a lack of trust towards the reception officers. The tension between the need 
for "identification"-instrumental for the provision of protection - and the reticence of the migrants to open up; and the presence of staff with no prior experience in the context of migration within the reception system. While basic needs are met, the provision of specialised care is left to improvisation.

"The topic of cultural mediators becomes essential, it's the first thing, language. I must be able to ask everything, get answers on everything." Health practitioner-T 27

"When he was asked 'were you a victim of violence?' He was troubled. But more (...) a refusal to remember, like 'talk to me about something else, please ask me something else,." Health practitioner-T16

"Because we work in the legal aspect we are seen as policemen, and they put up defences." Legal advisor-T2

"When I meet people for the first time I always ask. Usually with the intention of letting them know that if they have physical signs, obviously it's important for the Commission that these are documented. I say this and it's a little soft, like blackmailing: 'if you tell me this, it can help with the Commission', and at the same time it will help me get the information about the problem."Psychologist-T5

"I think the challenge is that there is no clarity in the procedure. With staff there is too much of a difference among reception officers: those who are trained and those who are not. So it's left to improvisation. [they are] not specialists in the field. So since staff are not homogeneous (...) if roles are confused, it's a problem. And it's a problem if you have to control it: it's a problem for people to trust you and share things that might inform you.” Legal advisor-T26

\section{Management of torture survivor cases within the reception and public health systems}

Prise en charge in the reception centres was reported to be challenging at different levels. The ability to provide adapted services within the reception structures was seen as being restricted due to the limited availability of human resources, while the public health system was seen as unprepared to respond to the specific needs of this population. One participant indicated that power dynamics embedded in the reception system, where reception officers exert control on the hosted migrants, could lead to the perception of officers as perpetrators, a situation that requires trained professionals to manage. This combination of factors tended to trigger the decision to rely on specialised actors with an expertise in the field.

"There is no enough time for all the work here, I bring work home with me. This is very frustrating and leads all us reception officers to burnout." Psychologist -T8

"[It's necessary] to have a different behaviour towards these people than with the other beneficiaries, a special care that is not always possible to provide or guarantee in the SPRAR. These people for example need, if they don't want to be in contact with the other beneficiaries, to have a room of their own. The team needs to work with everyone and cannot always dedicate attention to a single beneficiary and give them the attention they need." Legal advisor-T25

"The possibility for all of us to access [cultural] mediators at any time (...) If I want to speak with someone, for example in an emergency situation, I cannot. I have to book an appointment, postpone, sometimes it takes time, and sometimes this brings us far 
from the problem (...). The CSM don't have a specialist's knowledge in this field: while [specialist external actors] have a lot, a lot of cases, they are specialised in this kind of case." Psychologist-T5

"These people are specific cases.

We cannot treat them in the same way as someone going to physiotherapy for arthrosis. These people might do physiotherapy after a very strong trauma and must be followed in overall psychosomatic terms. Once more, this is a very delicate sector, I cannot say there is a service which can perform this function in terms of rehabilitation and psycho-dynamics. Certainly the rehabilitation services we have today work, but are not really dedicated to this aspect." Psychologist-T 13

"I had the feeling of being put in the role of oppressor. (...) It's difficult unless a reception officer is well trained to distinguish that this is symbolic and not related to him/ her personally. There are complicated (...) power dynamics, someone who has suffered torture, in the relation with a reception officer can relive it. The reception officer is the one who has to tell an adult that 'you cannot do this or that, you cannot cook in your room (...).” Legal advisor-T26

\section{Referral of torture survivors to specialised actors}

Reception officers acknowledged their reliance on specialised actors for the provision of specialised services and care. However, they also highlighted the limits of this reliance, due to the overstretched capacity and the length of time necessary for the prise en charge by these specialised actors. The waiting times were not seen as meeting the needs of the centre, or meeting the need to promptly submit medico-legal certification to the authorities adjudicating protection claims.

"She might tell me 'this person has a psychological vulnerability so maybe he should be referred for psychological support with [specialist external actors]. They also work with the forensic doctor, who checks the scars and can say if they are derived from torture, which I don't know how to do." Health practitioner-T7

"All the problems are around timing. Say maybe the appointment in Court is in 10 days and a report is not ready, so you don't know whether to delay the appointment. And it's important to understand at what point the person is of the medical process." Legal advisor-T12

"What $i$ have seen is that [specialist external actors] are overcrowded...but they still give appointments. (...) There are too many, too many cases in need." Health practitioner-T7

"One day I was with a colleague who accompanied a young man to [their clinic], and the reception officer, my colleague... they sent her outside and said "we need to talk to this person on his own and you must wait outside." So in that case we don't know anything about the person, we don't know what they talked about, what the doctor said, what he lived through or didn't live through, and so on. If you are not there, with the doctor, specifically, you cannot follow or organise." Cultural mediator-T23

"Sometimes we are lacking reference contacts, people who have the role of taking care of referrals (...) often we don't know who we should talk to (...) Knowing how sensitive these cases are." Psychologist-T24 


\section{Self-identified recommendations within the reception system}

First and foremost, interviewees called for training on the identification and management of torture survivor cases. The lack of training was seen as both a handicap to the reception officers and health practitioners and as a possible danger to the beneficiaries. An interest was expressed in having experts from the different external actors in the field share their experiences.

"We lack training. We have never had courses on this topic. We have always been considered a centre for suspected victims of trafficking. Torture, we've never even talked about it." Cultural mediator-T6

"Some have never worked in this sector, some do but may not be having the same sensitiveness. It would be useful to the team to have guidelines, because I might notice some things, but someone else might not. And I may be bound by confidentiality. My colleague who does not know anything might not understand the instructions given by the coordination team, and would then behave differently. Maybe we are not dealing with situations in the correct way. After this, after doing this internally in the centres, at the level of ASL there is really a need for a serious dedicated training, really serious."

Legal advisor-T2

"A training to enable us to face such delicate topics (...) If one doesn't know how to manage them, one can create further problems for the person who suffered. So it's a very, very, very delicate terrain." Psychologist-T13

"If we are not given the opportunity of training specifically, they [survivors of torture] can escape us. Some people are not skilled, it's not their fault, but they aren't, so it's necessary to distribute skills on these matters.” Psychologist-T13

Other recommendations included the importance of guaranteeing reception in smaller-sized structures, supported by specialised and multidisciplinary services. Services should be structured to develop social inclusion, relying on synergy between the different stakeholders. The responses also highlighted the importance of a guaranteed response that takes into consideration the individual and the specific needs of torture survivors. Public services stressed the need to have additional internal resources that can serve the response.

" $A$ smaller context, in distributed reception would be ideal (...) Also with the internal presence of a team for support, because (...) if he wakes up at night he needs someone, a reception officer who knows." Psychologist-T8

"In order for torture to emerge, what is required is a dedicated space and skills of the person managing the conversation. Much more than we can do today." Psychologist-T13

"Multi-professional, for sure: a psychiatric consultation or assistance on its own could not solve the issue (...) Social services because he must be slowly re-acquainted with a context which is even harder for him, because he is also foreign. [He] would find it difficult to integrate again in his natural environment, imagine in a foreign environment." Health practitioner-T22

"We come twice a week, so identification is already difficult. To offer continuous support with such a large number of guests is 
even harder. We can support, we can identify, but we need external assistance for sure, so more adequate situation would perhaps be a centre where people can be followed individually." Social worker-T10

"Someone vulnerable who is a victim of torture [will] find it more difficult to access jobs, trainings and so on, but I think there should be extra funds for this, because a vulnerable case should be supported." Psychologist-T8

"In terms of improvements, mediators are essential, possibly ours, and not from the [reception] centre." Health practitioner-T16

"Since the Municipality is involved in managing the SPRAR... the idea of creating a project, combining the various actors, the Prefecture the Municipality, us for the healthcare aspects and place them in a civic context to give a sense to their stay here, for months and months." Social worker-T21

\section{Discussion}

This study represents an in-depth qualitative exploration of the challenges in identification and linkage to care of torture survivors among the migrant and refugee population in the reception and public health systems in Italy. The study comes at a historic moment when the country is called to manage an influx of migrants and refugees - who are at high risk of having been exposed to torture and ill-treatment (Baker, 1992; Carsell et al., 2011; OHCHR, 2017)—while just having introduced torture as a crime in national legislation. Against this background, guidelines on the rehabilitation response and psychological treatment of victims of torture and violence were also recently published. Considerable confusion and uncertainty was observed in relation to the existence and implementation of procedures, both at national level and internally in the reception and health structures where they are to be implemented. The knowledge and understanding of the phenomenon of torture was mainly related to the personal exposure and/or prior experience of the individual, and was commonly associated and/or confused with episodes of trafficking or extreme violence faced by migrants/refugees in Libya.

Our results indicate how the detection and linkage to care of torture survivors among the migrant and refugee population principally occurs at the hands of nontrained health practitioners and reception officers, with no prior experience in the areas of torture and migration in general. This observation is consistent with similar studies (Asgary, Metalios, Smith, Paccione, 2006), and a recent review that identified that Germany and Croatia are the only European states with legislation on who is responsible for the identification of torture survivors (Towers, Reventlow, de Rengervé, de Witte, 2016). In addition to the lack of training, reception officers and health practitioners are confronted with a number of difficulties ranging from linguistic and cultural barriers - due to a lack or insufficient presence of cultural mediators-and mistrust and reticence of torture survivors.

This set of conditions may carry adverse consequences for the rehabilitation of survivors of torture among the migrant population. The lack of trust of survivors and their refusal to talk as a consequence of their experiences, also described elsewhere (Yawar, 2004), is further exacerbated by the dynamics in the reception system, where the role of reception officers appears to be linked to a degree of power and control over 
the refugees/migrants, evoking memories of and generating associations with perpetrators of torture and potentially impacting the development of a trusting relationship-a fundamental aspect in rehabilitation (Larson-Stoa, Jacobs, Jonathan, Poudyal, 2015). In light of this complex interaction, the lack of expertise and skills related to the identification of torture survivors, in combination with the lack of appropriate tools for identification, carries the risk of non-identification, and may conceivably cause harm when survivors are solicited for catharsis or ventilation (Jaranson, Kinzie, Friedman, Ortiz, Friedman, Southwick, et al., 2001), or when exposed to direct questioning. Our study also highlights the difficulty and possible risk of subjecting torture disclosure to time constraints in the frame of a legal procedure, rather than being considered an instrumental aspect of the rehabilitation process.

The available resources, including staff, were considered dramatically insufficient to respond to the needs of the migrant and refugee population and of torture survivors in particular. The presence of a small number of external actors specialised in torture represented a solution for the prise en charge of survivors in the region, but seemed insufficient in the face of the large number of referrals. Additionally, in several instances, referral was perceived as a means to comply with the timeframe of legal procedures, rather than as a step toward rehabilitation. The collaboration with services offered by specialised actors was characterised by a general lack of structured communication and referral systems, conceivably hampering the referral process and possibly impacting the effectiveness of the intervention. The recommendations formulated by the participants tended towards requests for additional resources in order to address the self-identified gaps in the area of training - considered essential for accurate identification and to avoid possible harm - and to strengthen the capacity of reception officers and health practitioners to appropriately handle cases and refer survivors.

The study faced a number of limitations, including being conducted in one specific geographical region of Italy, the small sample size and the focus on SPRAR and CAS centres, while CARA and centres for unaccompanied minors were excluded. Additionally, the study focused on care providers only, and thus no triangulation with experiences of the migrant/refugee population was done. A particular strength of the study was that it was conducted with frontline staff, capturing the situation "on the ground" while benefiting from the expertise of the practitioners from the MSF rehabilitation of victims of torture clinic in Rome.

A number of conclusions and recommendations can be drawn from this study. In light of the multiple gaps in the correct identification and case management of survivors of torture and ill-treatment, and the general difficulties in identifying such conditions, partly due to the lack of appropriate screening tools (Towers, Reventlow, de Rengervé, de Witte, 2016; Asgary, Metalios, Smith, Paccione, 2006; Visentin, Pelletti, Bajanowski, Ferrara, 2017), a considerable number of unidentified cases likely exist within the migrant and refugee population in Italy: the prevalence of torture is an overlooked issue by both the $\mathrm{MoH}$ and MoI. The lack of knowledge of the legal definition of torture has an impact not only on the correct identification of victims of 
torture but also on victims of other forms of violence, equally entitled to a range of services and specialised care. It is paramount that cases who face similar violence or criminal acts, without falling under the UNCAT definition, are correctly identified and referred to specialised services. This would prevent delay in the necessary delivery of care and avoid excessive workload for the clinics specialised in the rehabilitation of torture survivors.

While the legislative tools exist, defining the crime of torture to ensure the right of torture survivors to access rehabilitative care (OHCHR, 2012), proper assessment of reception needs (European Union, 2013), and provision of specific measures of assistance including adequate psychological support (Decree Law, no. 142, 2015) and while guidelines to orient the rehabilitative intervention were issued (Ministry of Health, 2017), they urgently need to be reinforced through dissemination, coupled with training and implementation. This should be combined with clear instructions on how identification should be conducted and, in the long run, development of tools to allow/help identification. Such reinforcement should at the very least consist of relevant training - as foreseen by relevant legislation (European Union, 2013) - for all reception officers employed in the reception structures and health and social practitioners at the public level.

Other trainings for health practitioners and social workers in public health services, and for reception officers employed in reception structures, should focus on migration-related topics to strengthen their sensitivity and the adoption a culturally adapted approaches with the migrant population, which would facilitate the emergence or identification of the torture condition. Trainings should be designed and tailored to fit the specificities of each profession involved.

Professional cultural mediation should be systematically provided in reception centres and public health structures to overcome language and cultural barriers, to establish and facilitate relationships between reception officers and beneficiaries, and to enhance the chances of detection or self-reporting of physical or psychological symptoms (Flores, 2005). It is essential that public health structures and general practitioners work with the systematic support of dedicated and trained cultural mediators without having to rely on cultural mediators employed by reception centres, in order to guarantee strict respect of confidentiality and avoid any possible conflict of interest.

Furthermore, we recommend that the Italian government allocates funds to support the existing expertise in the mixed private-public sector and for the development of specialised structures within the public health services, employing dedicated multidisciplinary teams of experienced medical and non-medical personnel and including cultural mediators as part of the interdisciplinary model. This would offer a conducive environment (far from the possible forms of control present in the reception structures) for torture survivors to develop a sense of trust and rapport with those involved in their rehabilitation. Additionally, considering that housing constitutes a major social determinant in health outcomes, alternative solutions to the current reception measures should be explored to meet the subjective needs of torture survivors and to strengthen rather than inhibit the rehabilitative process 
( Ziersch, Walsh, Due, Duivesteyn, 2017).

In conclusion, our study identified

a lack of awareness and a vacuum of (the implementation of) procedures for identification and referral of torture survivors among the migrant population arriving in Italy. These essential processes are relegated to non-trained and often inexperienced professionals at the different levels of the reception system and public health care sector. Additional resources and structured interventions are urgently needed, in the form of developing and implementing procedures, training and dedicated interdisciplinary services.

\section{Acknowledgements}

We acknowledge with gratitude the general practitioners and the personnel of the selected reception centres and the subdistricts in the Rome ASL 6 for their enthusiastic participation in this study. Without their contribution this article could never have been written. We would also like to show our gratitude to the Direction of the ASL Rome 6 for the collaboration and for allowing Médecins Sans Frontières, Italy Mission, to conduct this study in its territory. Additional thanks to MSF colleagues from the clinic for Victims of Torture in Rome for providing their inputs, suggestions and reflections on the topic.

A special posthumous acknowledgment goes to Mrs. Maria Grazia Germani, who worked as Responsible for the Social Services Department ASL 6, Rome Italy. Mrs. Germani's contribution has been instrumental for the identification of reception centers and the sub-district teams of ASL Rome 6 and for facilitating the contact with the principal investigator.

\section{Funding}

The training programme and open access publications costs were funded by the Department for International Development (DFID), UK and La Fondation Veuve Emile Metz-Tesch (Luxembourg). The funders had no role in study design, data collection and analysis, decision to publish, or preparation of the manuscript.

\section{References}

Asgary, RG., Metalios, EE. , Smith, CL., Paccione, GA. (2006). Evaluating asylum seekers/torture survivors in urban primary care: a collaborative approach at the Bronx Human Rights Clinic. Health and human rights, 9(2):164-79.

Baker, R. (1992). Psychological consequences for tortured refugees seeking asylum and refugee status in Europe. In: Basoglu M. editor (Ed), Torture and Its Consequences: Current Treatment Approaches (pp. 83-101). Cambridge, England: Cambridge University Press.

Braun, V., Clarke, V. (2006). Using thematic analysis in psychology. Qualitative Research in Psychology, 3(2):77-101.

Carswell, K., Blackburn, P., \& Barker, C. (2011). The relationship between trauma, post-migration problems and the psychological well-being of refugees and asylum seekers. Int $\mathcal{F}$ Soc Psychiatry, 57(2):107-19.

Creswell, J. (2007). Qualitative Inquiry $\mathcal{E}$ Research Design: Choosing Among Five Approaches. Thousand Oaks, CA, USA: Sage Publications, Inc.

Decree Law, no.142. (2015). Attuazione della direttiva 2013/33/UE recante norme relative all'accoglienza dei richiedenti protezione internazionale, nonche' della direttiva 2013/32/UE, recante procedure comuni ai fini del riconoscimento e della revoca dello status di protezione internazionale, Decreto Legislativo 18 agosto 2015, no. 142. [Implementation of the directive 2013/33/UE on current norms regulating the reception of asylum seekers].

De Maio, G., Pettinicchio, V. (2018). Accoglienza e cura delle vittime di tortura a Roma, 30 anni di esperienze. Osservatorio Romano, Tredicesimo Rapporto Report on the reception conditions and rehabilitation for victims of torture in Rome, 30 years of experience. [Report on the recep- 
tion conditions and rehabilitation for victims of torture in Rome, 30 years of experience.]. Centro Studi e Ricerche Idos.

European Union., (2013). Directive 2013/33/EU of the European Parliament and of the Council of 26 June 2013 laying down standards for the reception of applicants for international protection.

Flores, G. (2005). The impact of medical interpreter services on the quality of health care: a systematic review. Medical care research and review: MCRR, 62(3):255-99.

Frontex., (2017). Central Mediterranean Route. Frontex. http://frontex.europa.eu/trends-androutes/central-mediterranean-route/.

Jaranson, JM., Kinzie, JD., Friedman, M., Ortiz, SD., Friedman, MJ., Southwick, S., et al. (2001). Assessment, Diagnosis, and Intervention. In: Gerrity, E., Tuma, F., Keane, T.M., (eds). The Mental Health Consequences of Torture The Plenum Series on Stress and Coping. Boston, MA, USA: Springer, pp. 249-275.

Kirmayer, LJ., Narasiah, L., Munoz, M., Rashid, M., Ryder, AG., Guzder, J., et al.(2011). Common mental health problems in immigrants and refugees: general approach in primary care. in $C M A \mathcal{F}$ Canadian Medical Association journal = journal de l'Association medicale canadienne, 183(12), E959-67.

Larson-Stoa, D., Jacobs, GA., Jonathan, A., Poudyal, B. (2015). Effect of counseling by paraprofessionals on depression, anxiety, somatization, and functioning in Indonesian torture survivors. Torture, 25(2):1-11.

Ministero dell'Interno. [Ministry of the Interior.] (2009). Ministero dell'Interno, European Union. Linee di Indirizzo per il Riconoscimento della Figura Professionale del Mediatore Interculturale, del Gruppo di Lavoro Istituzionale per la promozione della Mediazione Interculturale. Rome, Italy: Centro Informazione e Educazione allo Sviluppo. [Guidelines on the recognition of intercultural mediators.] Rome, Italy.

Ministero dell'Interno. [Ministry of the Interior.] (2017). Cruscotto Statistico Giornaliero 12 Aprile 2017. Rome, Italy: Ministero dell'Interno. [Daily statistics on 12th April 2017.] Rome, Italy. http://www.libertaciviliimmigrazione.dlci.interno. gov.it/sites/default/files/allegati/cruscotto_statistico_giornaliero_12_aprile_2017.pdf.

Ministero dell'Interno. [Ministry of the Interior.] (2017). Ministero dell'Interno. Schema di Capitolato di Appalto. [Contract documents.] Rome, Italy. http://www.libertaciviliimmigrazione.dlci. interno.gov.it/sites/default/files/allegati/schema_ di_capitolato_di_appalto_p.pdf.

Ministero della Salute. [Ministry of Health.] (2017) Linee guida per la programmazione degli interventi di assistenza e riabilitazione nonché per il trattamento dei disturbi psichici dei titolari dello status di rifugiato e dello status di protezione sussidiaria che hanno subito torture, stupri o altre forme gravi di violenza psicologica, fisica o sessuale. [Guidelines for the programming of intervention of support and rehabiliatation programs, including for the treatment of mental health disorders affecting refugees and asylum seekers entitled to subsidiary protection, victims of torture and of cruel or other forms of inhumane degrading treatment, psychological, physical violence or sexual violence.] Rome, Italy.

OHCHR, UN Committee Against Torture (2012). Convention against Torture and other Cruel, Inhuman or Degrading Treatment or Punishment.

OHCHR, UN Committee Against Torture (2012). General Comment no. 3: Implementation of Article 14 by State Parties.

OHCHR, \& United Nations Human Rights - Office of the High Commissioner( 2017). Two-thirds of torture victims supported by UN Fund are migrants and refugees. New York, USA. http://www. ohchr.org/EN/NewsEvents/Pages/DisplayNews. aspx? NewsID=21533\&LangID $=\mathrm{E}$.

OSCE, Regional meeting on Rehabilitation for Victims of Torture for countries in the OSCE region (2016). Good Practices and Current Challenges in the Rehabilitation of Torture Survivors - discussion paper, June 23rd 2016. Copenhagen, Denmark.

Sousa, CA. (2013). Political violence, collective functioning and health: A review of the literature. Medicine, Conflict and Survival, 29(3): 169-97.

SPRAR., (2017). System of Protection for refugees and asylum seekers [Sistema de Protezione per Richiedenti Asilo e Rifugiati. SPRAR - English.] Rome, Italy]

Towers, R., Reventlow, M., de Rengervé, H. , de Witte, M. (2016). Recognising victims of torture in national asylum procedures - $A$ comparative overview of early identification of victims and their access to medico-legal reports in asylum-receiving countries. Copenhagen, Denmark: IRCT.

UNHCR (2017). Operational portal - refugee situations. Mediterranean situation. https:// data2.unhcr.org/en/situations/mediterranean/ location/5205\#category-1. 
UNSMIL, United Nations Support Mission in Libya, United Nations Human Rights - Office of the High Commissioner (2016). "Detained and dehumanised": Report on human rights abuses against migrants in Libya. Libya.

Visentin, S., Pelletti, G., Bajanowski, T., Ferrara, SD. (2017). Methodology for the identification of vulnerable asylum seekers. International journal of legal medicine.

Wenzel, T. (2007) Torture. Current opinion in psychiatry, 20 (5):491-6.

Yawar, A. (2004). Healing in survivors of torture. Journal of the Royal Society of Medicine, 97(8): 366-70.

Ziersch, A., Walsh, M., Due, C., Duivesteyn, E.(2017). Exploring the Relationship between Housing and Health for Refugees and Asylum Seekers in South Australia: A Qualitative Study. International journal of environmental research and public health, 14(9), 1036. 